\title{
Characteristics of a Japanese Adult Twin Database of High School Graduates
}

\author{
Syuichi Ooki ${ }^{\prime}$ Yuji Okazaki ${ }^{2}$ and Akio Asaka ${ }^{3}$ \\ 'Department of Health Science, Ishikawa Prefectural Nursing University, Kahoku, Ishikawa, Japan \\ ${ }^{2}$ Department of Psychiatry, School of Medicine, Mie University, Tsu, Mie, Japan \\ ${ }^{3}$ Joto Hospital, Joto Kofu, Yamanashi, Japan
}

$T^{\text {nh }}$ his paper profiles a unique cohort of adult Japanese twins. The database contains more than 700 twin pairs, aged 18 to 66 years, who are all graduates of the secondary school attached to the faculty of education of the University of Tokyo. This school was established in 1948, when the study of twins was burgeoning in Japan, and about 10 to 20 pairs of twins have been admitted there every year to participate in studies on twins in education and in related projects. The zygosity of all twins was determined carefully on the basis of various sources. Data from the perinatal period to adulthood were linkable using ID numbers. Follow-up surveys in the field of medical genetics were performed in 1985, 1989 and 1999. For the third survey, which was sent and received exclusively by mail, the distribution and collection process was also assessed in detail. The response rate was around $40 \%$, which statistically was influenced mainly by previous participation and sex. The limitation of this cohort is its selection bias concerning socioeconomic status and its imbalance in favor of monozygotic pairs.

Although many twin registries have been established around the world, including those in Asian countries (Sumathipala et al., 2000; Sung et al., 2002; Yang et al., 2002), no nationwide or population-based twin registry exists in Japan.

Previously, we have reported elsewhere on the progress of a database of young Japanese twins born between 1968 and 1990 and their families (Ooki \& Yokoyama, 2003) through using methods such as collecting data from mothers belonging to associations for the parents of twins.

It is considerably more difficult to collect systematic data on adult twins in Japan than young twins. Birth records are not allowed to be used in Japan as a tool to identify individuals. Additionally, Sumathipala et al. (2003) report that in Sri Lanka birth records are not effective for obtaining data on adults. Therefore, we used alternative data sources such as the historically unique data source specific to Japan which we describe in this paper.

\section{Methods \\ Participants}

The twins were all graduates of the secondary education school attached to the faculty of education of the University of Tokyo. This school is famous in Japan because many twins study there. The school was established in 1948, when the study of twins was burgeoning in Japan, and has always had a unique entrance system. The school collects applications from twins in addition to applications from the general student population. About 50 pairs of twins of all sex and zygosity combinations, aged 11 or 12 years and living in the Tokyo metropolitan area, take an examination every year, of which about 10 to 20 pairs are admitted. The entrance examination taken by twins is the same as that taken by the other applicants. Mothers of all of the twin applicants must complete and hand in a Twins Protocol Questionnaire, which gathers information on family structure, obstetrical findings on the mothers, and the twins' physical growth, zygosity, and motor and mental development from birth through 11 years of age. One parent of each applicant, usually the mother, participates in a medical interview conducted by two or three interviewers (including, from 1988 on, two of the present authors, Ooki and Asaka), in which their responses to the questionnaire are checked carefully. During their six years of enrolment, the twins participate in observational studies for educational and related projects. Zygosity is diagnosed strictly by the best possible way, depending on the year of entrance. For example, many anthropometric characteristics and blood groups were used in the early years. Recently, many genetic markers or DNA polymorphisms have been used (Ooki \& Asaka, 2004). All data from the perinatal periods through childhood, school age, and adulthood were linkable theoretically using individual specific ID numbers, though in practice the linkages have been partial so far.

Received 30 April, 2004; accepted 23 July, 2004.

Address for correspondence: Syuichi Ooki, Department of Health Science, Ishikawa Prefectural Nursing University, Tsu7-1 Nakanuma, Kahoku, Ishikawa, 929-1212, Japan.E-mail: sooki@kj8.so-net.ne.jp 


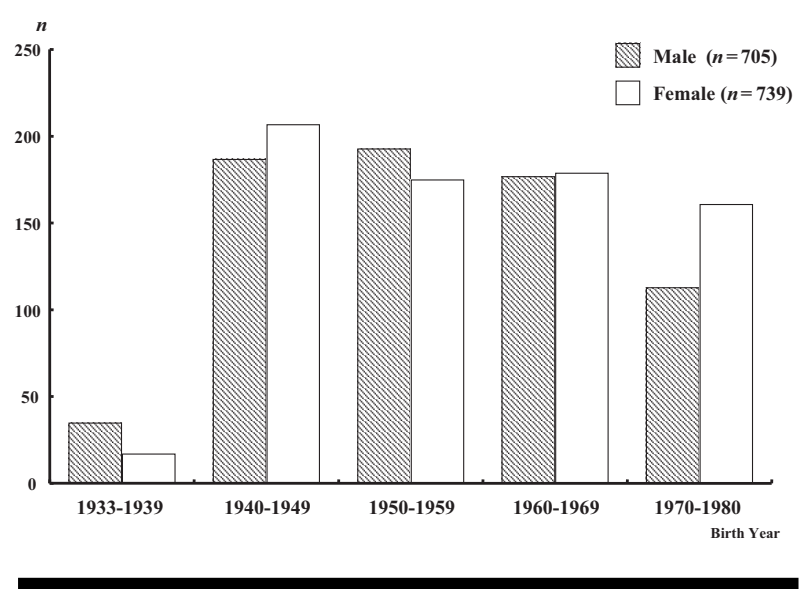

Figure 1

Birth-year distribution of the participants.

A total of 722 pairs of twins, consisting of 586 monozygotic (MZ) (283 male-male [MZM] and 303 female-female [MZF]) and 136 dizygotic (DZ) (44 male-male [DZSSM], 41 female-female [DZSSF], and 51 opposite-sex [DZOS]), have graduated from this school through 1999. Cumulative frequencies according to the combination of sex and zygosity are increasing almost proportionally year by year. The birth-year distribution of this cohort is shown in Figure 1.

\section{Outline of Follow-Up Studies}

The three follow-up studies are outlined in Table 1. The core items in all three surveys included questions about occupation, marital status, number of children, body weight and height, drinking habits, smoking habits, food preference, medical history. The third follow-up study was performed in 1999. Considering the 10-year gap between the second and third surveys, we substantially reconstructed the database for future studies (Ooki, 2002). The process of finding and contacting participants by mail was also examined.

\section{Mailed Survey in the Third Follow-Up Study}

Figure 2 provides a flowchart of the response and follow-up for the mailed survey. A total of 1444 twins (722 twin pairs) were identified as graduates through the end of the 1998-1999 school year. First, postcards containing a brief introduction to our research and an invitation to participate were sent to 1244 individuals, asking for their cooperation in the survey. As Table 2 shows, there were no marked differences in sex or zygosity as to the percentage of possible participants actually contacted. For 77 twins, we tried to get the address of one co-twin from the other, resulting in 14 more addresses. We then mailed the questionnaires, along with return envelopes, to 1215 individuals, and 1207 of those individuals received them. To raise the response rate, we asked again for the cooperation of 135 twins whose co-twin had already answered the questionnaire. This resulted in 57 more responses. Therefore, in total we received 435 responses.

\section{Statistical Analysis}

The response rate for the third follow-up study was summarized. Multiple logistic regression analysis was performed to clarify the factors affecting participation in the third follow-up survey. Each response in a completed questionnaire was determined as an independent variable. Zygosity, sex, and age at the time of the survey were determined as explanatory variables. Participation in the second survey was also considered. Data was not available on regular occupation and marital status of nonrespondents for all three surveys. Therefore, it was not possible to perform logistic regression analysis taking these factors into consideration because of insufficient informative sample size. We compared regular occupation and marital status of twins who completed all three surveys with those who did not complete all three surveys. All statistical analysis was performed using SAS for Windows (SAS Institute, 1997).

\section{$\overline{\text { Results }}$}

The response rates to the questionnaire surveys according to zygosity and sex are shown in Table 2 . Among same-sex pairs, the response rate was much lower among males than females. Among pairs, the response rate was highest in female $M Z$ pairs and lowest in male DZ pairs. A total of 1215 questionnaires were mailed out with 1207 being received by participants. Of the 435 total respondents, 378 (Group 1) returned the answers directly while 57 other twins (Group 2) responded only after their co-

Table 1

Outline of Three Follow-Up Surveys

\begin{tabular}{|c|c|c|c|c|c|c|c|}
\hline Survey & Year of survey & $\begin{array}{l}\text { Number of } \\
\text { all graduates }\end{array}$ & $\begin{array}{c}\text { Age of } \\
\text { graduates }\end{array}$ & $\begin{array}{l}\text { Response rate } \\
\text { (individuals) }\end{array}$ & $\begin{array}{l}\text { Response rate } \\
\text { (pairs) }\end{array}$ & $\begin{array}{c}\text { Medical } \\
\text { examination }\end{array}$ & Medical topics \\
\hline First & 1985 & 541 pairs & $18-52$ & Unknown & $28.6 \%(120 / 420)$ & 44 pairs & Diabetes, personality \\
\hline Second & 1989 & 573 pairs & $19-55$ & $45.5 \%(435 / 957)$ & $37.5 \%(167 / 445)$ & 27 pairs & $\begin{array}{l}\text { Bone mineral density, } \\
\text { osteoporoses }\end{array}$ \\
\hline Third & 1999 & 722 pairs & $19-66$ & $36.0 \%(435 / 1207)$ & $31.0 \%(174 / 562)$ & Not performed & $\begin{array}{l}\text { Multiple risk factor } \\
\text { syndrome }\end{array}$ \\
\hline
\end{tabular}




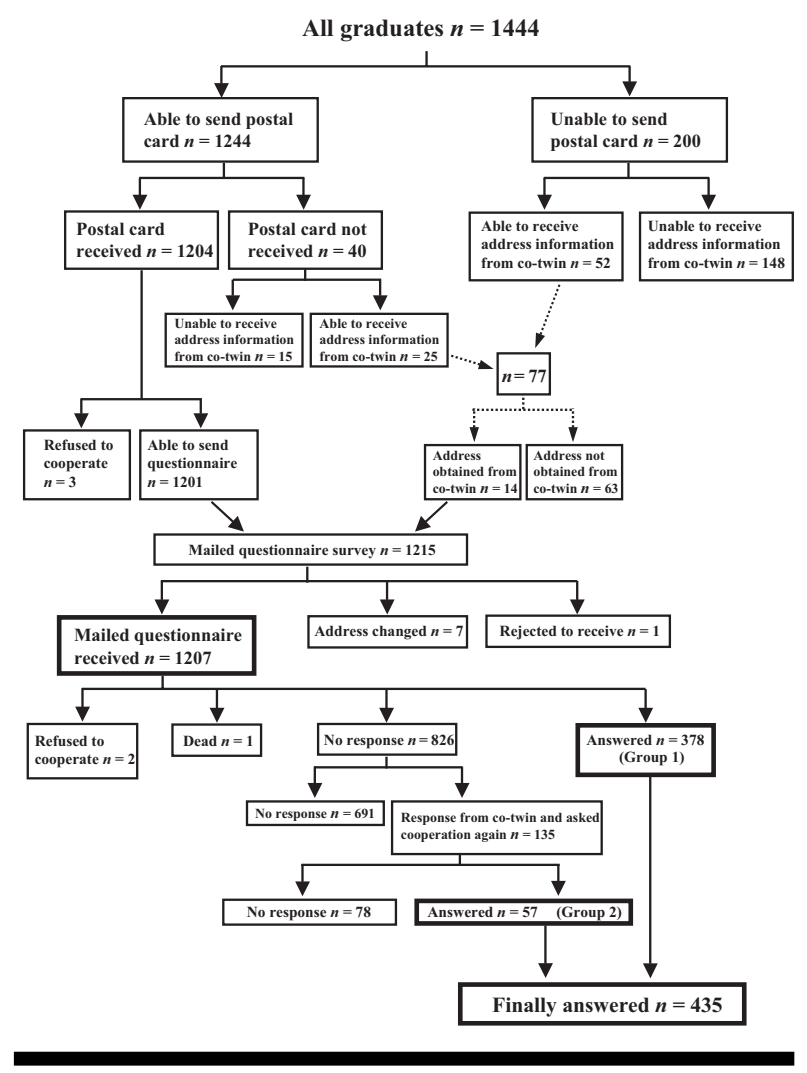

Figure 2

Summary of response and follow-up for the 1999 mailed survey.

twin asked them to. The response rate of females was higher than that of males in both groups.

The results of logistic regression analysis are as follows. Participation in the third survey depended mainly on sex $(p<.0001$, odds ratio $=2.174,95 \%$ confidence intervals $=1.705-2.773$ ). The response rate was much higher among females than males. If participation in the second survey was considered, this variable was the most influential $(p<.0001$, odds ratio $=4.295,95 \%$ confidence intervals $=3.237-$ 5.698 ), and in that case the effect of sex was diminished $(p<.0001$, odds ratio $=1.870,95 \%$ confidence intervals $=1.410-2.480)$. No other variable, such as age at time of survey and zygosity met the .01 significance level for entry into the model.

Figure 3 summarizes participation in all three surveys. Data from single participants, a twin who responded without a response from the co-twin, in the first survey were excluded because of a lack of records. Thirty-six pairs participated in all three surveys. Of these, 33 pairs were MZ (5 male pairs and 28 female pairs) and 3 pairs were DZ (2 female pairs and 1 opposite-sex pair). The characteristics of the $272(74+40+158)$ twins who did not respond to the third survey but had responded to at least one of the first two surveys were compared with 94 twins who remained in all three surveys. Significant sex difference was observed between the drop-out group and remainder group $(p<.0001)$. More females $(35 \%$; $73 / 208)$ than males $(13 \% ; 21 / 158)$ remained in the survey. No significant difference was observed as to zygosity, marital status, regular occupation (yes or no), and age at time of survey between drop-out group and remainder group.

According to the third survey, at least $80.9 \%$ (352/435) of the twins expressed their intention to cooperate to some extent in the future. The futurecooperation rate among MZ $(81.9 \%)$ was slightly

Table 2

Response Rate in the Third Follow-Up Survey According to Sex and Zygosity

\begin{tabular}{|c|c|c|c|c|c|c|c|}
\hline & \multicolumn{2}{|c|}{ Monozygotic } & \multicolumn{2}{|c|}{ Same-sex dizygotic } & \multicolumn{2}{|c|}{ Opposite-sex dizygotic } & \multirow[t]{2}{*}{ Total } \\
\hline & Male & Female & Male & Female & Male & Female & \\
\hline $\begin{array}{l}\text { Participants } \\
\text { (individual twins) }\end{array}$ & 566 & 606 & 88 & 82 & 51 & 51 & 1444 \\
\hline $\begin{array}{l}\text { Number of possible } \\
\text { participants actually } \\
\text { contacted }(\%)\end{array}$ & 80.9 & 86.1 & 85.2 & 84.1 & 80.4 & 82.4 & 83.6 \\
\hline $\begin{array}{l}\text { Response rate } \\
\quad \text { (individual twins) (\%) }\end{array}$ & $\begin{array}{l}26.6 \\
(122 / 458)\end{array}$ & $\begin{array}{l}45.6 \\
(238 / 522)\end{array}$ & $\begin{array}{l}21.3 \\
(16 / 75)\end{array}$ & $\begin{array}{l}30.4 \\
(21 / 69)\end{array}$ & $\begin{array}{l}43.9 \\
(18 / 41)\end{array}$ & $\begin{array}{l}47.6 \\
(20 / 42)\end{array}$ & $\begin{array}{l}36.0 \\
(435 / 1207)\end{array}$ \\
\hline Group 1* & $\begin{array}{l}23.1 \\
(106 / 458)\end{array}$ & $\begin{array}{l}40.8 \\
(213 / 522)\end{array}$ & $\begin{array}{l}17.3 \\
(13 / 75)\end{array}$ & $\begin{array}{l}24.6 \\
(17 / 69)\end{array}$ & $\begin{array}{l}31.7 \\
(13 / 41)\end{array}$ & $\begin{array}{l}38.1 \\
(16 / 42)\end{array}$ & $\begin{array}{l}31.3 \\
(378 / 1207)\end{array}$ \\
\hline Group 2** & $\begin{array}{l}28.6 \\
(16 / 56)\end{array}$ & $\begin{array}{l}54.3 \\
(25 / 46)\end{array}$ & $\begin{array}{l}27.3 \\
(3 / 11)\end{array}$ & $\begin{array}{l}80.0 \\
(4 / 5)\end{array}$ & $\begin{array}{l}50.0 \\
(5 / 10)\end{array}$ & $\begin{array}{l}57.1 \\
(4 / 7)\end{array}$ & $\begin{array}{l}42.2 \\
(57 / 135)\end{array}$ \\
\hline $\begin{array}{l}\text { Response rate (complete } \\
\text { twin pairs) (\%) }\end{array}$ & $\begin{array}{l}18.7 \\
(39 / 209)\end{array}$ & $\begin{array}{l}42.9 \\
(106 / 247)\end{array}$ & $\begin{array}{l}11.4 \\
(4 / 35)\end{array}$ & $\begin{array}{l}30.3 \\
(10 / 33)\end{array}$ & & & $\begin{array}{l}31.0 \\
(174 / 562)\end{array}$ \\
\hline
\end{tabular}

Note: *Returned questionnaire without prompting.

**Returned questionnaire after prompting by a co-twin. 


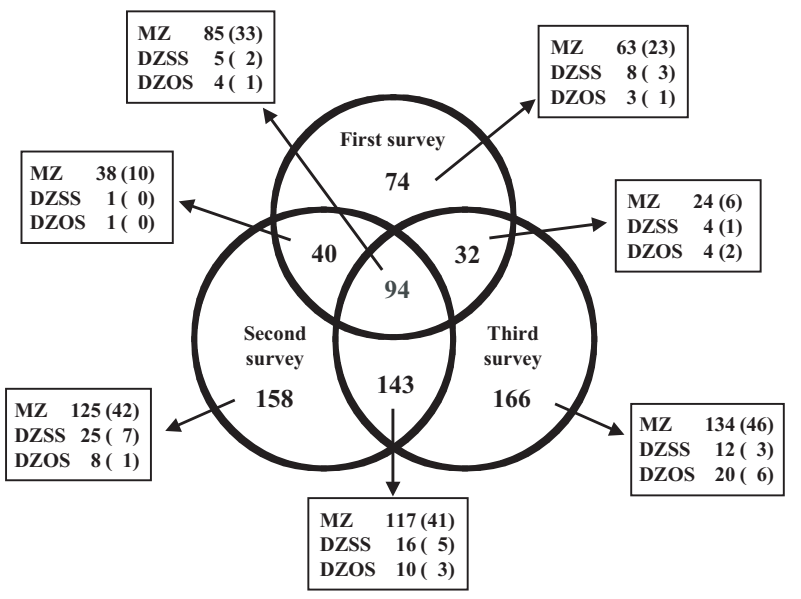

Figure 3

Circumstances of participation in the three follow-up surveys.

Note: Number of individuals are shown with the number of complete pairs in parentheses.

higher than that among DZ (76.0\%). There was no sex difference $(80.8 \%$ for males and $81.0 \%$ for females).

\section{Discussion}

Sex was the most important factor in deciding participation in the third follow-up survey, if participation in the second survey was not considered. According to population-based studies of twins performed by Cockburn et al. (2001), this tendency was especially marked in the younger adult age group. Among age groups by sex in the third survey, the highest response rate, $61.4 \%$ (97/158), was obtained from females in their thirties, and the lowest, $15.2 \%$ (14/92), was from males in their twenties. Participation in the second survey, when considered, became the most influential factor. Moreover, no sex difference was observed in the third survey as to participants' intentions for future surveys, supporting the tendency of fixation of the respondents. It was comparatively difficult to collect data from younger males, especially in DZ twins, from this cohort.

As shown in Figure 2, the effort to obtain address information for one co-twin from the other provided only minimal additional possible respondents.

In all surveys postage-paid envelopes were provided to respondents, so there was no need to stamp the envelopes individually. This may have contributed to the low response rate because, according to Duffy \& Martin (2001), response rates increase by increasing the numbers of postage stamps.

Table 3 provides a description of the cohort. Though the sample is small, this cohort has several unique characteristics. Firstly, the zygosity of every participant was determined carefully on the basis of various sources. This is a very important feature, as zygosity classification using DNA markers is considerably troublesome in Japan, from an ethical viewpoint. Secondly, data from the perinatal period to adulthood can be linked by using individual ID numbers. This feature is advantageous for longitudinal studies or for examining the so-called fetal origin hypothesis.

The greatest limitation of this cohort is its selection biases based on the sampling process itself. All participants are graduates of the high school attached to the university. They lived in the Tokyo metropolitan area when they were enrolled at the school, and all passed the entrance examination. Participants are not representative of adults in general in Japan regarding socioeconomic status and some abilities. This selection bias would be fatal in some study designs. For example, the smoking rate was $41.7 \%$ for males and $8.4 \%$ for females in the third survey, which is much lower than in the Japanese general population, even considering age distribution.

\section{Table 3}

Outline of the Japanese Adult Twin Database

\begin{tabular}{ll} 
Name of cohort & Japanese adult twin database of high-school graduates \\
Country & Japan \\
Kind of ascertainment & Information from school and follow-up survey \\
Follow-up survey & Three times (see Table 1) \\
Opposite-sex twins & Yes \\
Number of pairs & 722 (62 pairs are recruited newly in the next survey, planned for 2004. About 10 to 20 pairs will be added every year.) \\
Birth year & 1933-1980 \\
Primary interest & Genetic study of lifestyle (eating, smoking, drinking, and sleep habits, stress reaction, physical exercise, etc.) and \\
& lifestyle-related disease, cognitive ability, and longevity. Fetal origin hypothesis. Psychology as to twinship. Functional \\
molecular genetics. & 1. The zygosity of same-sex pairs was determined by detailed anthropometric similarity or DNA/genetic markers. \\
Comments & 2. Twins are followed longitudinally. \\
& 3. All data from perinatal period to adulthood can be linked using individual ID numbers. \\
& 4. Family data have been collected. \\
& 5. Functional molecular genetic analysis of twin pairs who are discordant in relation to certain diseases are planned. \\
\hline
\end{tabular}


Moreover, there is a zygosity imbalance in favor of $\mathrm{MZ}$ twins, in contrast to the small sample size of DZ pairs, in relation to the MZ/DZ ratio in Japan (Imaizumi \& Nonaka, 1997). This difference may also result from the entrance process. If only DZ twins who are similar in their abilities are admitted together, this could be a potential source of bias. It is difficult to estimate the long-term effects of these selection biases.

We need to maintain and make the most of this historically important cohort in Japan, but take into consideration these characteristics and limitations. The authors plan to study the functional molecular genetics of twin pairs who are discordant in relation to certain diseases; such twin studies have been rare in Japan.

\section{Acknowledgments}

We would like to thank the many collaborators of the secondary school attached to the faculty of education of the University of Tokyo. We also would like to thank many researchers who have been maintaining this historically important cohort. We would gratefully acknowledge the help of Toshimi Ooma and Yuko Sugiura regarding the analysis of the data. This work was supported in part by a Grant-in-Aid from the Ministry of Health, Labour and Welfare of Japan (Principle Investigator, Yuji Okazaki), and by a Grant-in-Aid from the Ministry of Education, Culture, Sports, Science and Technology of Japan (Principle Investigator, Syuichi Ooki).

\section{References}

Cockburn, M., Hamilton, A., Zadnick, J., Cozen, W., \& Mack, T. M. (2001). Development and representativeness of a large population-based cohort of native Californian twins. Twin Research, 4, 242-250.

Duffy, D. L., \& Martin, N. G. (2001). Increasing the response rate to a mailed questionnaire by including more stamps on the return envelope: A cotwin control study. Twin Research, 4, 71-72.

Imaizumi, Y., \& Nonaka, K. (1997). The twinning rates by zygosity in Japan, 1975-1994. Acta Geneticae Medica et Gemellologiae, 46, 9-22.

Ooki, S. (2002). Statistical genetic analysis of multiple risk factor syndrome in Japan. Japanese Journal of Health and Human Ecology, 68, 123-132.

Ooki, S., \& Yokoyama, Y. (2003). Reference birth weight, length, chest circumference, and head circumference by gestational age in Japanese twins. Journal of Epidemiology, 13, 333-341.

Ooki, S., \& Asaka, A. (2004). Zygosity diagnosis in young twins by questionnaire for twins' mothers and twins' self-reports. Twin Research, 7, 5-12.

SAS Institute Inc. (1997). SAS/STAT Software: Change and enhancement through Release 6.2. Cray, NC: Author.

Sumathipala, A., Fernando, D. J. S., Siribaddana, S. H., Abeysingha N. M. R., Jayasekare, R. W., Dissanayake, V. H. W., \& De Silva, N. (2000). Establishing a twin register in Sri Lanka. Twin Research, 3, 202-204.

Sumathipala, A., Siribaddana, S. H., Abeysingha N. M. R., De Silva, N., Fernando, D. J. S., Dayaratne, D. A. R. K., De Silva, D., Warnasuriya N. D., \& Hotopf, M. (2003). Challenges in recruiting older twins for the Sri Lankan twin registry. Twin Research, 6, 67-71.

Sung, J., Cho, S-H., Cho, S-I., Duffy, D. L., Kim, J-H., Kim, H., Park, K. S., \& Park, S. K. (2002). The Korean twin registry: Methods, current stage, and interim results. Twin Research, 5, 394-400.

Yang, H., Li, X., Cao, W., Lu, J., Wang, T., Zhan, S., Hu, Y., \& Li, L. (2002). Chinese National Twin Registry as a resource for genetic epidemiologic studies of common and complex diseases in China. Twin Research, 5, 347-351. 